\title{
Linalool oxide: generalist plant based lure for mosquito disease vectors
}

Vincent O. Nyasembe ${ }^{1}$, David P. Tchouassi ${ }^{1}$, Charles M. Mbogo ${ }^{2}$, Catherine L. Sole ${ }^{3}$, Christian Pirk ${ }^{3}$ and Baldwyn Torto ${ }^{1 *}$

\begin{abstract}
Background: Lack of effective vaccines and therapeutics for important arboviral diseases such as Rift Valley fever (RVF) and dengue, necessitates continuous monitoring of vector populations for infections in them. Plant-based lures as surveillance tools has the potential of targeting mosquitoes of both sexes and females of varied physiological states; yet such lures are lacking for vectors of these diseases. Here, we present evidence of the effectiveness of linalool oxide (LO), a single plant-based lure previously developed for malaria vectors in trapping RVF vectors, Aedes mcintoshi and Aedes ochraceus, and dengue vector, Aedes aegypti.
\end{abstract}

Methods: For RVF vectors, we used CDC traps to evaluate the performance of $L O$ against three vertebrate-based lures: $\mathrm{CO}_{2}$ (dry ice), BioGent (BG) lure, and HONAD (a blend of aldehydes) in 2 experiments with Completely Randomized design: 1) using unlit $C D C$ traps baited separately with $L O, H O N A D$ and $B G-l u r e$, and unlit $C D C$ trap $+\mathrm{CO}_{2}$ and lit CDC trap as controls, 2) similar treatments but with inclusion of $\mathrm{CO}_{2}$ to all the traps. For dengue vectors, $\mathrm{LO}$ was evaluated against $\mathrm{BG}$ lure using $\mathrm{BG}$ sentinel traps, in a $3 \times 6$ Latin Square design, first as single lures and then combined with $\mathrm{CO}_{2}$ and traps baited with $\mathrm{CO}_{2}$ included as controls. Trap captures were compared between the treatments using Chi square and GLM.

Results: Low captures of RVF vectors were recorded for all lures in the absence of $\mathrm{CO}_{2}$ with no significant difference between them. When combined with $\mathrm{CO}_{2}, \mathrm{LO}$ performance in trapping these vectors was comparable to BG-lure and $\mathrm{HONAD}$ but it was less effective than the lit CDC trap. In the absence of $\mathrm{CO}_{2}$, $\mathrm{LO}$ performed comparably with the BGlure in trapping female Ae. aegypti, but with significantly higher males recorded in traps baited with the plant-based lure. When $\mathrm{CO}_{2}$ was added, LO was significantly better than the BG-lure with a 2.8- fold increase in captures of male Ae. aegypti.

Conclusions: These results highlight the potential of $L O$ as a generalist plant-based lure for mosquito disease vectors, pending further assessment of possible specificity in their response profile to the different stereoisomers of this compound.

Keywords: Rift Valley fever, Dengue, Climate-change, Stereoisomers, Arboviral diseases, Odor-bait, Vector ecology, Aedes mcintoshi, Aedes ochraceus, Aedes aegypti

\footnotetext{
* Correspondence: btorto@icipe.org

'Behavioral and Chemical Ecology Department, International Centre of Insect Physiology and Ecology, P.O Box 30772-00100, Nairobi, Kenya

Full list of author information is available at the end of the article
} 


\section{Background}

Vector-borne diseases exert a huge toll on global infectious disease burden. Rift Valley fever (RVF) and dengue represent two important mosquito-borne arboviral diseases, which continue to spread, evident from numerous disease outbreaks in various parts of the world $[1,2]$. Rift Valley fever is an epizootic disease mainly occurring in Africa and the Arabian Peninsula, with outbreaks leading to devastating loss of millions of livestock and thousands of human deaths [3-7]. On the other hand, dengue, which mainly affects humans, has a worldwide distribution where outbreaks have been reported in over 110 countries [8]. Approximately 3 billion of the world population is at risk of dengue infection and over 100 million reported cases and up to 25000 fatalities annually $[1,9]$. Both RVF and dengue have episodic outbreak patterns with low viral activities during the interepidemic periods [2, 10, 11]. Rift Valley fever outbreaks are associated with weather anomalies such as widespread elevated rainfall while that of dengue is closely linked to urbanization and transportation, which creates conducive breeding sites for the respective vector populations, and subsequent virus amplification and transmission [12-14]. In the recent past, there has been a growing concern of the possibility of further spread of both diseases to new areas, particularly to Asia and Europe, in the wake of current climate change [14, 15]. In Kenya, the key primary vectors implicated in the transmission of RVF are the flood water Aedes mcintoshi and Aedes ochraceus $[16,17]$ while that of dengue fever is Aedes aegypti [18]. Lack of safe and effective vaccines and therapeutics against both diseases [1, 19], makes studies on the vectors geared towards developing efficient monitoring or control tools a priority $[12,20]$. Effective monitoring of infection/viruses in vectors requires highly effective sampling tools.

The successful use of odor bait technology in population reduction of Glossina morsitans morsitans Westwood and G. pallidipes Austen in the Zambezi Valley of Zimbabwe [21], has heightened prospects for its similar application in the surveillance and control of blood feeding insects [22]. For blood feeding mosquitoes, a number of odor baits targeting specific species have been developed with considerable success, but these baits are mainly based on vertebrate host odors [23-26]. These baits have been widely employed along with carbon dioxide, which is associated with vertebrate breath and is known to elicit long range activation of host seeking behavior in most mosquito species [27]. In addition, the synthetic carbon dioxide that is extensively employed together with these lures is expensive and presents logistical challenges for use in remote areas where these diseases are endemic [28]. These challenges can be circumvented by employing plant based lures as adult mosquitoes of all physiological states and both sexes utilize nectar for energy [29,30]. However, except for a few laboratory studies to identify plant odors attractive to Ae. aegypti [30], little effort has been made to develop plant based lures for the management of RVF and dengue vectors.

In an effort to develop more potent lures for these vector species, we investigated the potential of linalool oxide (LO), a single-component plant based lure initially developed for the malaria vectors [31, 32], in trapping the primary vectors for RVF, Ae. mcintoshi and Ae. ochraceus; and dengue fever, Ae. aegypti. This study presents the first evidence of effectiveness of a plant-based lure in trapping primary RVF and dengue vectors.

\section{Methods}

Study sites

The study was conducted at two sites in Kenya: Garissa County in North Eastern region where RVF is endemic [17] and Kilifi County in Coastal region where dengue fever is endemic [33]. The two sites were selected based on the relative abundance of the target vectors of these diseases i.e. Aedes (Neomelaniconion) mcintoshi and Aedes (Aedimorphus) ochraceus for RVF, and Aedes aegypti for dengue [25, 34, 35].

Garissa County is largely semi-arid with two unreliable rainy seasons a year; short rains occurring between October and December and the long rains between March and May. Typical average rainfall ranges from $300 \mathrm{~mm}$ to $500 \mathrm{~mm}$ annually. Annual temperatures range from a minimum of $14{ }^{\circ} \mathrm{C}$ and a maximum of $34{ }^{\circ} \mathrm{C}$. The region also experiences periodic ElNiño/Southern Oscillation (ENSO) phenomena which predispose it to epidemic RVF outbreaks [12]. The altitude of the study area varies between $18 \mathrm{~m}$ and $75 \mathrm{~m}$ above sea level with the coordinates of $1.5988^{\circ} \mathrm{S}$ and $40.5135^{\circ} \mathrm{E}$. The area is inhabited mainly by pastoralists who engage in keeping livestock such as sheep, goats, cattle, camels, and donkeys, and migrate throughout the year in search of pastures and water. Vegetation in the area is predominantly shrubs and acacia bushes. Traps were set up in Sangailu, Ijara, Masalani, Korisa and Kotile communities of Ijara subCounty which have a lot of visible dambos in the landscape (shallow depressions that hold water during flooding and serve as breeding sites for flood water Aedes).

Kilifi County is relatively wet with two rainfall seasons; the short rains between October and December, and long monsoon rains between April and July, with an average annual rainfall of $950 \mathrm{~mm}$. The annual temperatures range from a minimum of $21{ }^{\circ} \mathrm{C}$ and a maximum of $32{ }^{\circ} \mathrm{C}$. The area lies $3.6333^{\circ} \mathrm{S}$ and $39.8500^{\circ} \mathrm{E}$ with an altitude of between 9 and $50 \mathrm{~m}$. In this area, trapping was conducted in an urban setting with largely modified 
topography and vegetation providing numerous breeding sites for Ae. aegypti.

\section{Ethical statement}

In Garissa, field trappings were conducted away from homesteads and on community land as authorized by area chiefs and community elders after explaining the purpose of the study to them. In Kilifi, informed consent was obtained from the persons in charge of public sites or heads of the homesteads where the studies were conducted as well as the area chiefs.

\section{Chemicals used}

The lures tested in this study included commercial synthetic linalool oxide, commercial BioGent (BG) lure (a 3-component blend comprising ammonia, lactic acid and caproic acid developed for Aedes aegypti), and HONAD (a 4-component blend comprising heptanal, octanal, nonanal and decanal, an animal-based lure developed at the International Centre of Insect Physiology and Ecology (icipe) in Nairobi for RVF vectors). The composition of HONAD is $2 \mathrm{mg} / \mathrm{ml}$ heptanal, $0.5 \mathrm{mg} / \mathrm{ml}$ octanal, $0.1 \mathrm{mg} / \mathrm{ml}$ nonanal and $0.1 \mathrm{mg} / \mathrm{ml}$ decanal [24].

The synthetic standards of the following compounds were used: linalool oxide (Aldrich, mixture of stereoisomers with furanoid form, $99.5 \%$ and $0.5 \%$ pyranoid form), heptanal (Sigma-Aldrich, $98 \%$ ), octanal (SigmaAldrich, $98 \%$ ), nonanal (Sigma-Aldrich, 98 \%), and decanal (Sigma-Aldrich, $98 \%$ ). Both LO and HONAD were released from a rubber septa.

\section{Optimization of field attractive doses of linalool oxide and determination of the release rate}

Linalool oxide was tested at the concentration reported in our previous work $(2 \mathrm{ng} / \mu \mathrm{l})$ [32] including two tenfold higher concentrations $(20 \mathrm{ng} / \mu \mathrm{l}$ and $200 \mathrm{ng} / \mu \mathrm{l})$ to find out if the threshold of odor response differs among the mosquito species. This was carried out at both Garissa and Kilifi field sites.

In Garissa, initial assessment of the dose responses was carried out in Sangailu involving three unlit CDC traps each baited with one of the three LO doses and $\mathrm{CO}_{2}$ and randomly placed in the vegetation around dambos and away from homesteads at $40 \mathrm{~m}$ inter-trap distance. This was replicated three times with each replicate set at a new location daily. The traps were activated at 18:00 hr and retrieved 06:00 hr the following morning. The trapped mosquitoes were knocked down using dry ice, sorted, counted and then placed in eppendorf tubes and preserved in liquid nitrogen for transport to the laboratory at icipe in Nairobi. Once at icipe the samples were stored at $-80^{\circ} \mathrm{C}$ until identification using morphological keys [36, 37].
Similarly, BG sentinel traps baited with each of the LO doses and $\mathrm{CO}_{2}$ was used to optimize for the most attractive dose for dengue vectors in Kilifi. Traps were placed at a distance of $40 \mathrm{~m}$ apart around three different locations (two breeding sites comprising abandoned tires and fish ponds which had Ae. aegypti larvae and one next to homestead with no obvious breeding sites) for two alternate days and one night. The daytime trapping was carried out from 06:00 - 18:00 hr while the night trapping was done from 18:00 - 06:00 hr. The trap captures were emptied and counted at the end of each trapping.

Release rate studies were carried out at the icipe Duduville campus in Nairobi $\left(1.22^{\circ} \mathrm{S}, 36.88^{\circ} \mathrm{E} ; \approx 1,600 \mathrm{~m}\right.$ above sea level) with temperature variations between 12 and $28{ }^{\circ} \mathrm{C}$ and humidity of $60-70 \%$. The release rate of LO at the optimal dose $(20 \mathrm{ng} / \mu \mathrm{l})$ over $12 \mathrm{hr}$ period was determined by applying $100 \mu \mathrm{l}$ of the LO solution on a rubber septa, allowing the solvent to evaporate completely in a fume chamber before exposing the rubber septa outside. Volatiles were collected from the rubber septa in a $40 \mathrm{ml}$ quickfit chamber (ARS, Gainesville, FL, $\mathrm{USA}^{\circ}$ ) and passing air over it at a flow rate of $260 \mathrm{ml} /$ min into an adsorbent Super-Q trap for $1 \mathrm{hr}$. Volatiles were collected after every three hour-interval over a $12 \mathrm{hr}$ period as follows: $1 \mathrm{hr}, 3 \mathrm{hr}, 6 \mathrm{hr}, 9 \mathrm{hr}$ and $12 \mathrm{hr}$; with the rubber septa re-exposed outside after every collection. The Super-Q trap was eluted with dichloromethane and analyzed on coupled gas chromatography-mass spectrometry (GC/MS). The GC/MS analysis was carried out in the splitless injection mode using an Agilent Technologies 7890 gas chromatograph coupled to a 5975C inert XL EI/CI mass spectrometer (EI, $70 \mathrm{eV}$, Agilent, Palo Alto, California, USA) equipped with an HP-5 column $(30 \mathrm{~m} \times 0.25 \mathrm{~mm}$ ID $\times 0.25 \mu \mathrm{m}$ film thickness, Agilent, Palo Alto, California, USA). Helium was used as the carrier gas at a flow rate of $1.2 \mathrm{ml} / \mathrm{min}$. The oven temperature was held at $35{ }^{\circ} \mathrm{C}$ for $3 \mathrm{~min}$, then programmed to increase at $10{ }^{\circ} \mathrm{C} / \mathrm{min}$ to $280{ }^{\circ} \mathrm{C}$ and maintained at this temperature for $5 \mathrm{~min}$. Three replicates were carried out at each time interval and the average peak areas for the two stereoisomers of LO $((Z)$ - and $(E)$-linalool oxide (furanoid form)) used to quantify release rates against an external calibration with synthetic LO.

\section{Study design}

\section{Effectiveness of LO in trapping Rift Valley fever vectors} Selection of a suitable trap type

In a preliminary study, the performance of CDC light trap and BG sentinel trap were compared in terms of captures to determine the best trap type for RVF vectors. Three unlit CDC traps and three BG sentinel traps separately baited with $\mathrm{LO}+\mathrm{CO}_{2}, \mathrm{HONAD}+\mathrm{CO}_{2}$ and $\mathrm{BG}$ 
lure $+\mathrm{CO}_{2}$ were randomly set around vegetation with water-containing dambos away from homesteads. With an inter-trap distance of $40 \mathrm{~m}$, the experiment was replicated five times. Based on consistent higher captures compared to BG sentinel trap (Additional file 1: Figure S1), CDC light trap was selected for subsequent evaluation of the effectiveness of the different lures in trapping RVF vectors.

\section{Evaluation of lures}

Two sets of experiments were carried out. In the first experiment, 5 treatments comprising unlit $\mathrm{CDC}$ traps each baited singly with $\mathrm{CO}_{2}$, LO, HONAD, BG lure and lit $\mathrm{CDC}$ trap without $\mathrm{CO}_{2}$ were compared. A total of five replications were carried out in a Completely Randomized experimental design with each replicate set in a new location in either Sangailu or Kotile sites. In the second experimental setup, similar 5 sets of treatments comprising unlit $\mathrm{CDC}$ traps each baited with $\mathrm{CO}_{2}, \mathrm{LO}+\mathrm{CO}_{2}$, $\mathrm{HONAD}+\mathrm{CO}_{2}$, BG lure $+\mathrm{CO}_{2}$ and a lit $\mathrm{CDC}$ trap + $\mathrm{CO}_{2}$. Completely Randomized study design was conducted over five different sites (Sangailu, Ijara, Masalani, Korisa, and Kotile) located approximately 30-100 km apart. At each site, traps were set up following a Completely Randomized experimental design as described above. The study was carried out over 12 nights with each night treated as a replicate. Each site was sampled at least twice and all the treatments rotated through all the sites. In both experiments, traps were activated shortly after sunset (18:00 hrs) and removed in the morning (06:00 hrs). The synthetic carbon dioxide in the form of dry ice was released from an Igloos thermos container (2 L; John W Hock, Gainesville, FL, USA). Trapped mosquitoes were knocked down, preserved and transported to icipe as described above. Once at icipe the samples were stored at $-80{ }^{\circ} \mathrm{C}$ until identification using morphological keys [36, 37] and the number of target species counted.

\section{Effectiveness of LO in trapping dengue vectors}

Mosquito trapping was done within the urban centre in Kilifi. Two sets of experiments were carried out. In the first experiment, three treatments comprising BG sentinel traps each baited with $\mathrm{CO}_{2}$, LO and BG lure were compared at six sites; two near productive breeding sites comprising abandoned tires or fish ponds (sites with $A e$. agypti larvae), two in vegetation, and two around homesteads. A $3 \times 6$ Latin Square study design was used comprising six days and six nights. The traps were rotated through all the sites with each treatment replicated twice in each of the six sites day and night, giving a total of 12 replicates. In the second experiment, three treatments comprising $\mathrm{BG}$ sentinel traps each baited with $\mathrm{CO}_{2}, \mathrm{LO}$ $+\mathrm{CO}_{2}$ and $\mathrm{BG}$ lure $+\mathrm{CO}_{2}$ were compared in a $3 \times 6$
Latin Square experimental design as described above with a total of 12 replicates. Day time mosquito trapping was done between 06:00 hrs and 18:00 hrs while night time trapping was done between 18:00 hrs and 06:00 hrs the following day. The carbon dioxide was dispensed as described earlier. Trap collections were removed at 06:00 hr and 18:00 hrs every day, knocked down, counted and similarly preserved and transported as described earlier. Once at icipe the samples were stored at $-80{ }^{\circ} \mathrm{C}$ until identification using morphological keys [36, 37].

\section{Statistical analysis}

The difference in the release rates of $(Z)$ - and $(E)$ - Linalool oxide (furanoid) over time was detected by one-way ANOVA after reciprocal transformation of release rates. The proportions of total number of mosquitoes trapped by each dose of $\mathrm{LO}$ were subjected to Chi square. Similarly, trap capture between CDC and BG sentinel traps to determine the best trap type for RVF vectors was compared using Chi square. To determine the effectiveness of the different lures in trapping disease vectors, the numbers of mosquitoes per treatment were first fitted with general linear model (GLM) with Poisson distribution and then negative-binomial error structure and log link in case of over dispersion as described by White and Bennetts [38] using R 2.15.1 software [39]. For RVF vectors, trap treatment (lure) was modeled as factors, with $\mathrm{BG}$ lure and $\mathrm{BG}$ lure $+\mathrm{CO}_{2}$ serving as reference for traps without and with $\mathrm{CO}_{2}$, respectively. Trap captures in the presence and absence of $\mathrm{CO}_{2}$ was compared using Chi square. In the case of dengue vectors, trap treatment and time of the day, were modeled as factors, with BG lure or $\mathrm{BG}$ lure $+\mathrm{CO}_{2}$ serving as reference for traps without and with $\mathrm{CO}_{2}$, respectively. Similarly, trap captures in the presence and absence of $\mathrm{CO}_{2}$ was compared using Chi square. The incidence rate ratios (IRR), a measure of the likelihood that mosquito species chose treatments other than the reference treatment (traps baited with BG lure or BG lure $+\mathrm{CO}_{2}$ ) and their $P$-values were estimated. The IRR for the reference is 1 (unity) and values above this indicates better performance and values below under performance of the treatments relative to the control. Given the high number of male mosquitoes caught in the traps for Ae. aegypti, captures were compared for both sexes. In addition, day and night captures of Ae. aegypti were compared using Chi square goodness-of-fit test. All statistical analyses were done at $95 \%$ confidence interval.

\section{Results}

Optimal field attractive dose of $L O$ and its release rates We determined that for both RVF and dengue vectors the most attractive dose was $20 \mathrm{ng} / \mu \mathrm{l}$, which recorded 
the highest mosquito trap captures. However, a significant difference between the trap captures for the three doses was only evident for Aedes agypti $(P<0.001)$ but not for Ae. mcintoshi and Ae. ochraceus (Table 1). The average release rate at this dose was $1.98 \mathrm{ng} / \mathrm{hr}$ and $1.92 \mathrm{ng} / \mathrm{hr}$ for $(Z)$ - and $(E)$-linalool oxide (furanoid), respectively, with no difference in the release rates of both isomers over the $12 \mathrm{hr}$ period $\left(\mathrm{F}_{(4,10)}=0.746, P=0.582\right.$ and $\mathrm{F}_{(4,10)}=0.965, P=0.468$, respectively) (Fig. 1a). $\mathrm{GC} /$ MS analysis further revealed that the commercial synthetic standard of LO used also contained trace amounts of the pyranoid form of $(Z)$ - and $(E)$-linalool oxide (Fig. 1b).

\section{Linalool oxide effective in trapping Rift Valley fever vectors}

In the first experiment, low numbers of Ae. mcintoshi and Ae. ochraceus were caught in the absence of $\mathrm{CO}_{2}$ (Ae. mcintoshi: $\mathrm{LO}=4, \mathrm{HONAD}=1, \mathrm{BG}$ lure $=4$, lit $\mathrm{CDC}$ trap $=5 ;$ Ae. ochraceus: $\mathrm{LO}=5, \mathrm{HONAD}=7, \mathrm{BG}$ lure $=2$, lit $C D C$ trap $=6$ ) with no significant difference in the mosquito captures between the traps baited with these lures $(P=0.33)$. In the second experiment, a total of 267 Ae. mcintoshi and 141 Ae. ochraceus were caught in 12 replicate trials. The lit $\mathrm{CDC}$ traps $+\mathrm{CO}_{2}$ caught significantly more Ae. mcintoshi than the unlit CDC traps baited with $\mathrm{BG}$ lure $+\mathrm{CO}_{2}(\mathrm{IRR}=2.1, P<0.001)$, while the unlit $\mathrm{CDC}$ trap $+\mathrm{CO}_{2}$ caught the least number of this species (IRR $=0.1, P<0.001$, Table 2). HONAD + $\mathrm{CO}_{2}$ and $\mathrm{LO}+\mathrm{CO}_{2}$ did not differ significantly from the BG lure $+\mathrm{CO}_{2}$ in trapping Ae. mcintoshi (IRR $=1.1$ and 1.3, respectively, Table 2). Similarly, the lit CDC trap + $\mathrm{CO}_{2}$ caught significantly a higher number of Ae. ochraceus than the BG lure (IRR $=2.6, P<0.001$ ), with the unlit $\mathrm{CDC}$ trap $+\mathrm{CO}_{2}$ catching the least number (IRR $=0.4$, $P<0.05$, Table 2). Again, trap captures with HONAD + $\mathrm{CO}_{2}$ and $\mathrm{LO}+\mathrm{CO}_{2}$ did not differ significantly from that captured by the BG lure $+\mathrm{CO}_{2}$ (IRR $=0.8$ and 1.1, respectively, Table 2).

\section{Linalool oxide effective in trapping dengue vectors Aedes aegypti}

In the first experiment, 628 females and 804 males of Ae. aegypti were caught. There was no significant

Table 1 Trap captures of Rift Valley fever and dengue vectors to different doses of Linalool oxide

\begin{tabular}{lllll}
\hline Mosquito species & $2 \mathrm{ng} / \mu \mathrm{l}$ & $20 \mathrm{ng} / \mathrm{\mu l}$ & $200 \mathrm{ng} / \mu \mathrm{l}$ & $P$-value \\
\hline Aedes mcintoshi & 19 & 28 & 24 & 0.276 \\
Aedes ochraceus & 11 & 21 & 15 & 0.088 \\
Aedes aegypti & 297 & 391 & 346 & $<0.001$ \\
\hline
\end{tabular}

The values represent the total number of mosquitoes caught. Unlit CDC traps were used in trapping Ae. mcintoshi and Ae. ochraceus, while BG sentinel trap was used in trapping Ae. aegypti difference between LO and BG lure in trapping female Ae. aegypti $(\mathrm{IRR}=1, P=0.89$, Table 3$)$, but $\mathrm{LO}$ trapped 1.4 fold more males than the BG lure $(P<0.01$, Table 3$)$. Traps baited with carbon dioxide alone were less attractive compared with those baited with the BG lure in trapping both male and female Ae. aegypti (IRR $=0.4, P<0.001$; and IRR $=0.3, P<0.001$, respectively, Table 3 ). When the lures were each combined with $\mathrm{CO}_{2}$, a total of $2087 \mathrm{fe}-$ male and 2415 male Ae aegypti were caught. An additive effect on trap capture was observed $(P<0.001)$, with LO trapping significantly more males (IRR $=2.8, P<0.001$, Table 3) than the BG lure. The number of male and female Ae. aegypti caught were significantly higher during the day than at night (IRR $=3, P<0.001$ and IRR $=1.3, P<$ 0.001 , respectively).

\section{Discussion}

In our previous study, we had demonstrated the high efficacy of LO alone and in combination with carbon dioxide in trapping the malaria vectors $A n$. gambiae s.l. [32]. Our results showed that despite targeting different mosquito disease vectors, the three lures LO, BG and HONAD alone and in combination with carbon dioxide varied in their effectiveness in trapping RVF vectors Ae. mcintochi and Ae. ochraceus and the dengue vector $A$ e. aegypti, as previously found for the malaria vectors An. gambiae s.l. [32]. Notably, whereas LO alone was effective in trapping both sexes of Ae aegypti, LO, BG lure and HONAD were only effective in trapping the two RVF vectors in the presence of $\mathrm{CO}_{2}$. The failure of the three lures to trap RVF vectors in the absence of $\mathrm{CO}_{2}$ perhaps explains the critical role played by this compound in host location and orientation by these vectors, which are highly zoophilic as opposed to the anthropophilic nature of Ae. aegypti and An. gambiae in agreement with previous studies [40].

Also, notably, besides a few laboratory-based bioassays to test the attractiveness of plant volatile extracts to Ae. aegypti $[41,42]$, this is the first field evidence of the potential of a plant-based compound in field trapping of RVF and dengue vectors. Linalool oxide compared favorably to the two vertebrate lures in trapping RVF and dengue vectors. This is particularly interesting given that $\mathrm{LO}$ is a single component lure capable of attracting a number of important mosquito species. Use of common chemical cues in host location has been demonstrated in several insect species. For instance, 1-octen-3-ol has been shown to play a key role in host location by several blood feeding insects including tsetse flies, stable flies, culicoides and mosquitoes [43-45]. These findings highlight the potential use of a single- or multi-component plant- 


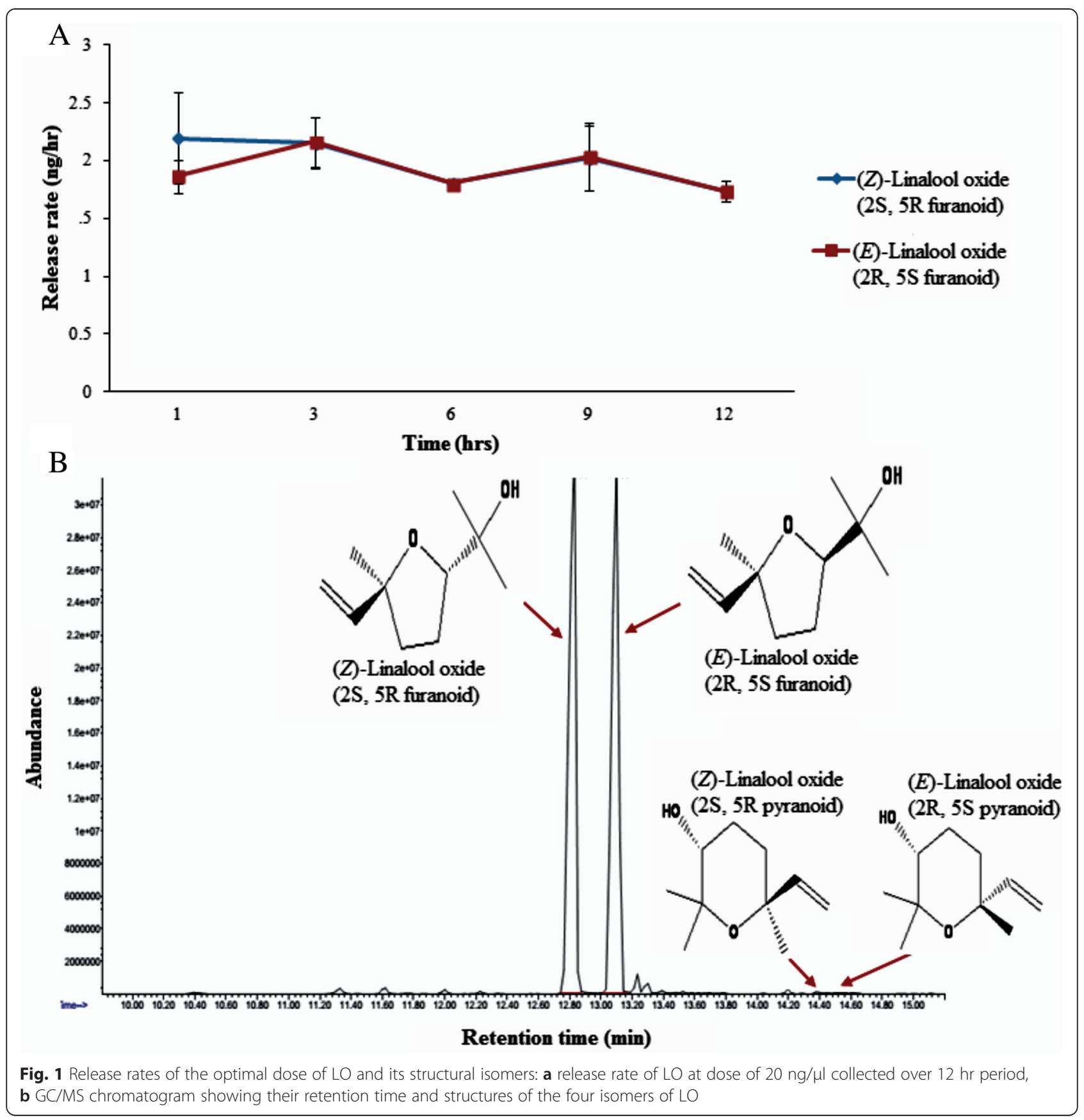

based lure for mosquito vector surveillance and control.

The fact that $\mathrm{CO}_{2}$-baited lit CDC traps performed better than $\mathrm{CO}_{2}$-baited unlit CDC traps baited with each of the three lures for RVF vectors, suggests the importance of visual cues in the behavior of these mosquitoes. As such, the interaction of visual and chemical cues could be exploited further for effective monitoring of these vectors. Therefore, with further development and formulations, linalool oxide and perhaps other yet to be identified plant odors may hold promise as possible plant-based alternatives to $\mathrm{CO}_{2}$ depending on the target mosquito species.

Furthermore, the presence of male Ae. aegypti in traps baited with LO is interesting. With the development of sterile insect technique as a population reduction tool for mosquito control, there has been a need to improve field based lures to target the male segment of the mosquito population for purposes of evaluating competency and survival of sterile males as compared to wild ones [46]. Plant-based lures have been suggested to hold potential in targeting this segment of the population 
Table 2 Trap captures of Rift Valley fever vectors captured by CDC trap baited with different lures

\begin{tabular}{lllll}
\hline Mosquito species & Lure & Sample size & Mean $\pm \mathrm{SEM}$ & $P$-value \\
\hline Aedes mcintoshi & $\mathrm{BG}$ lure $+\mathrm{CO}_{2}$ & 47 & $3.92 \pm 0.93$ & \\
& $\mathrm{CO}_{2}$ & 7 & $0.58 \pm 0.19$ & $<0.001$ \\
& $\mathrm{LO}+\mathrm{CO}_{2}$ & 59 & $4.92 \pm 1.56$ & 0.24 \\
& $\mathrm{HONAD}+\mathrm{CO}_{2}$ & 53 & $4.42 \pm 1.22$ & 0.55 \\
& $\mathrm{Lit} \mathrm{CDC}+\mathrm{CO}_{2}$ & 101 & $8.42 \pm 1.05$ & $<0.001$ \\
Aedes ochraceus & $\mathrm{BG}$ lure $+\mathrm{CO}_{2}$ & 24 & $2.00 \pm 0.63$ & \\
& $\mathrm{CO}_{2}$ & 10 & $0.83 \pm 0.27$ & $<0.05$ \\
& $\mathrm{LO}+\mathrm{CO}_{2}$ & 26 & $2.17 \pm 0.91$ & 0.78 \\
& $\mathrm{HONAD}+\mathrm{CO}_{2}$ & 19 & $1.58 \pm 0.63$ & 0.44 \\
& $\mathrm{Lit} \mathrm{CDC}+\mathrm{CO}_{2}$ & 62 & $5.17 \pm 1.14$ & $<0.001$ \\
\hline
\end{tabular}

Lit $\mathrm{CDC}$ trap was not baited with any lure except $\mathrm{CO}_{2}$. Total number of replicates $(N)=12$. SEM standard error of mean, $L O$ linalool oxide, $B G$ Biogent. BG lure $+\mathrm{CO}_{2}$ was used as reference and $P$-values for each treatment relative to it calculated

$[28,30]$. Therefore, our finding here suggests the potential of a phytochemical in trapping both male and female mosquito disease vectors.

LO is a chiral compound and the commercial synthetic standard used in our study as shown by our GC/ MS analysis consisted of tentatively identified racemic mixture of four enantiomers, $(2 \mathrm{R}, 5 \mathrm{~S})-(E)$-furanoid, $(2 \mathrm{~S}, 5 \mathrm{R})-(Z)$-furanoid, $(2 \mathrm{R}, 5 \mathrm{~S})-(E)$-pyranoid and (2S, 5R)$(Z)$-pyranoid. Therefore, it is likely that the differential efficacy of LO in trapping the different mosquito disease vectors and sexes can be attributed to the different enantiomeric forms of this compound, which needs further investigation. Interestingly, differential response of insects to different stereoisomers of certain semiochemicals has been reported. For example, the (1S,2'S) form of

Table 3 Trap captures of dengue vectors (Aedes aegypti) captured by BG trap baited with different lures

\begin{tabular}{|c|c|c|c|c|}
\hline Sex & Lure & Sample size & Mean \pm SE & $P$-value \\
\hline \multirow[t]{6}{*}{ Females } & BG lure & 257 & $32.13 \pm 9.48$ & \\
\hline & LO & 216 & $27.00 \pm 6.43$ & 0.89 \\
\hline & $\mathrm{CO}_{2}$ & 155 & $19.38 \pm 4.49$ & $<0.001$ \\
\hline & $\mathrm{BG}$ lure $+\mathrm{CO}_{2}$ & 998 & $124.75 \pm 53.54$ & \\
\hline & $\mathrm{LO}+\mathrm{CO}_{2}$ & 935 & $116.88 \pm 66.03$ & 0.15 \\
\hline & $\mathrm{CO}_{2}$ & 163 & $20.38 \pm 3.94$ & $<0.001$ \\
\hline \multirow[t]{6}{*}{ Males } & BG lure & 204 & $25.50 \pm 9.87$ & \\
\hline & LO & 416 & $52.00 \pm 17.08$ & $<0.01$ \\
\hline & $\mathrm{CO}_{2}$ & 174 & $21.75 \pm 4.75$ & $<0.001$ \\
\hline & $\mathrm{BG}$ lure $+\mathrm{CO}_{2}$ & 710 & $88.75 \pm 38.67$ & \\
\hline & $\mathrm{LO}+\mathrm{CO}_{2}$ & 1521 & $190.13 \pm 72.41$ & $<0.001$ \\
\hline & $\mathrm{CO}_{2}$ & 177 & $22.13 \pm 3.49$ & $<0.001$ \\
\hline
\end{tabular}

Total number of replicates $(\mathrm{N})=12$. SEM standard error of mean, $L O$ linalool oxide, $B G$ Biogent. $\mathrm{BG}$ lure or $\mathrm{BG}$ lure $+\mathrm{CO}_{2}$ was used as reference and $P$-values for the other non- $\mathrm{CO} 2$ and $\mathrm{CO}_{2}$ baited lures, respectively, calculated 1-[3-cyclohexen-1-ylcarbonyl]-2-methylpiperidine was found to be two-fold more repellent against Ae. aegypti than the (1R,2'S) form [47]. Similarly, Manduca sexta was shown to have a higher preference for plants producing (+)-linalool compared to those producing (-)-linalool [48]. Hence the present study provides a basis for further investigation into the potential of phytochemicals, especially those with chiral centres to address specificity in responses of different mosquito disease vectors to stereoisomers of these compounds.

\section{Conclusion}

We document the performance of LO in trapping the RVF vectors, Ae. mcintoshi and Ae. ochraceus, which compared favorably with the BG lure and HONAD, but better than the BG lure for female Ae. aegypti, the major vector of dengue. In the absence of carbon dioxide, this compound performed dismally in trapping RVF vectors but was comparable to the BG lure for trapping dengue vectors. However, linalool oxide was superior to the BG lure in trapping male Ae. aegypti in the presence or absence of carbon dioxide. These results highlight the potential of LO as a generalist plant-based lure for mosquito disease vectors, with room for further development to obtain a potent phytochemical attractant for the management of these vectors.

\section{Additional file}

Additional file 1: Figure S1. Comparision of unlit CDC trap and BG sentinel trap in trapping Rift Valley fever vectors. $N=5$, chi square was used to analyze count data. Bars capped with ${ }^{* *}$ are significantly different at 0.01. (PNG $10 \mathrm{~kb}$ )

\section{Abbreviations}

RVF: Rift Valley fever; LO: linalool oxide; BG: BioGent; HONAD: heptanal, octanal, nonanal and decanal; KEMRI: Kenya Medical Research Institute; GLM: generalized linear model; SIDA: Swedish International Development Cooperation Authority.

\section{Competing interests}

The authors declare that they have no competing interest and that the donors had no role in the drafting of this manuscript.

\section{Authors' contributions}

Conceived and designed the experiments: VON DPT CLS CP BT. Performed the experiments: VON DPT CMM BT. Analyzed the data: VON DPT BT. Wrote the paper: VON DPT CMM CLS CP BT. All authors approved the final version for submission.

\section{Acknowledgement}

We wish to appreciate the Kenya Medical Research Institute, Kilifi for providing logistical support for conducting this study in the area. Specifically, we wish to extend our appreciation to Dr. Joseph Mwangangi and Martha Njeri of KEMRI Kilifi for assistance with field logistics, and James Wauna, Richard M. Mugo and Jackson Kimani, of icipe for technical support. This study was funded by Swedish International Development Cooperation Agency (Sida) studentship to VON. 


\section{Author details}

'Behavioral and Chemical Ecology Department, International Centre of Insect Physiology and Ecology, P.O Box 30772-00100, Nairobi, Kenya. ${ }^{2}$ KEMRI \& Public Health Department, Centre for Geographic Medicine Research - Coast, KEMRI - Wellcome Trust Research Programme, Nairobi, Kenya. ${ }^{3}$ Department of Zoology and Entomology, University of Pretoria, Pretoria, South Africa.

\section{Received: 5 August 2015 Accepted: 28 October 2015} Published online: 09 November 2015

\section{References}

1. Bhatt S, Gething PW, Brady OJ, Messina JP, Farlow AW, Moyes $C L$, et al. The global distribution and burden of dengue. Nature. 2013;496(7446):504-7.

2. Gubler DJ. The global emergence/resurgence of arboviral diseases as public health problems. Archiv Med Res. 2002;33(4):330-42.

3. Davies F. Observations on the epidemiology of Rift Valley fever in Kenya. J Hyg. 1975;75(02):219-30.

4. Meegan JM. The Rift Valley fever epizootic in Egypt 1977-1978 1. Description of the epizootic and virological studies. Trans Royal Soc Trop Med Hyg. 1979;73(6):618-23.

5. Ksiazek T, Jouan A, Meegan J, Le Guenno B, Wilson M, Peters C, et al. Rift Valley fever among domestic animals in the recent West African outbreak. Res Virol. 1989;140:67-77.

6. McIntosh B, Russell D, Dos Santos I, Gear J. Rift Valley fever in humans in South Africa. South Afric Med J. 1980;58(20):803-6.

7. Ahmad K. More deaths from Rift valley fever in Saudi Arabia and Yemen. Lancet. 2000;356(9239):1422.

8. Ranjit S, Kissoon N. Dengue hemorrhagic fever and shock syndromes. Pediatr Crit Care Med. 2011;12(1):90-100

9. World Health Organization. Dengue: guidelines, diagnosis, treatment, prevention and control - new edition. Geneva: WHO; 2009. p. 23.

10. Davies F, Linthicum K, James A. Rainfall and epizootic Rift Valley fever. Bull World Health Org. 1985;63(5):941.

11. Linthicum KJ, Anyamba A, Tucker CJ, Kelley PW, Myers MF, Peters CJ. Climate and satellite indicators to forecast Rift Valley fever epidemics in Kenya. Science. 1999;285(5426):397-400.

12. Anyamba A, Chretien J-P, Small J, Tucker CJ, Formenty PB, Richardson JH, et al. Prediction of a Rift Valley fever outbreak. Proc Natl Acad Sci U S A. 2009;106(3):955-9

13. Viennet E, Ritchie SA, Faddy HM, Williams CR, Harley D. Epidemiology of dengue in a high-income country: a case study in Queensland Australia. Parasit Vectors. 2014;7:379.

14. Hales S, De Wet N, Maindonald J, Woodward A. Potential effect of population and climate changes on global distribution of dengue fever: an empirical model. Lancet. 2002;360(9336):830-4

15. Martin V, Chevalier V, Ceccato PN, Anyamba A, De Simone L, Lubroth J, et al. The impact of climate change on the epidemiology and control of Rift Valley fever. Revue Scientifique et Technique, Office International des Epizooties. 2008;27(2):413-26.

16. Linthicum K, Davies F, Kairo A, Bailey C. Rift Valley fever virus (family Bunyaviridae, genus Phlebovirus). Isolations from Diptera collected during an inter-epizootic period in Kenya. J Hyg (Lond). 1985;95(1):197-209.

17. Sang R, Kioko E, Lutomiah J, Warigia M, Ochieng C, O'Guinn M, et al. Rift Valley fever virus epidemic in Kenya, 2006/2007: the entomologic investigations. Amer J Trop Med Hyg. 2010;83(2 Suppl):28-37.

18. Newton E, Reiter P. A model of the transmission of dengue fever with an evaluation of the impact of ultra-low volume (ULV) insecticide applications on dengue epidemics. Amer Trop Med Hyg. 1992;47(6):709-20.

19. Ikegami T, Makino S. Rift valley fever vaccines. Vaccine. 2009;27:D69-72.

20. Spiegel J, Bennett S, Hattersley L, Hayden MH, Kittayapong P, Nalim S, et al Barriers and bridges to prevention and control of dengue: the need for a social-ecological approach. Ecohealth. 2005;2(4):273-90.

21. Vale G, Lovemore D, Flint S, Cockbill G. Odour-baited targets to control tsetse flies, Glossina spp. (Diptera: Glossinidae), in Zimbabwe. Bull Entomol Res. 1988;78(01):31-49.

22. Kline DL. Semiochemicals, traps/targets and mass trapping technology for mosquito management. J Amer Mosq Control Assoc. 2007:23(sp2):241-51.

23. Tchouassi DP, Sang R, Sole CL, Bastos AD, Mithoefer K, Torto B. Sheep skin odor improves trap captures of mosquito vectors of Rift Valley fever. PLoS Negl Trop Dis. 2012;6(11):e1879.
24. Tchouassi DP, Sang $R$, Sole $C L$, Bastos AD, Teal PE, Borgemeister $C$, et al. Common host-derived chemicals increase catches of disease-transmitting mosquitoes and can improve early warning systems for Rift Valley fever Virus. PLoS Negl Trop Dis. 2013;7(1):e2007.

25. Owino EA, Sang R, Sole CL, Pirk C, Mbogo C, Torto B. Field evaluation of natural human odours and the biogent-synthetic lure in trapping Aedes aegypti, vector of dengue and chikungunya viruses in Kenya. Parasit Vectors. 2014;7(1):451.

26. Silva IM, Eiras ÁE, Kline DL, Bernier UR. Laboratory evaluation of mosquito traps baited with a synthetic human odor blend to capture Aedes aegypti. J Am Mosq Contr Ass. 2005;21(2):229-33.

27. Gillies M. The role of carbon dioxide in host-finding by mosquitoes (Diptera: Culicidae): a review. Bull Entomol Res. 1980;70:525-32.

28. Turner SL, Li N, Guda T, Githure J, Cardé RT, Ray A. Ultra-prolonged activation of $\mathrm{CO}_{2}$-sensing neurons disorients mosquitoes. Nature. 2011;474(7349):87-91.

29. Foster WA. Phytochemicals as population sampling lures. J Am Mosq Control Assoc. 2008;24(1):138-46.

30. Nyasembe VO, Torto B. Volatile phytochemicals as mosquito semiochemicals. Phytochem Lett. 2013;8:196-201.

31. Nyasembe VO, Teal PEA, Mukabana WR, Tumlinson JH, Torto B. Behavioural response of the malaria vectorAnopheles gambiae to host plant volatiles and synthetic blends. Parasit Vectors. 2012;5:234.

32. Nyasembe VO, Tchouassi DP, Kirwa HK, Foster WA, Teal PE, Borgemeister C, et al. Development and assessment of plant-based synthetic odor baits for surveillance and control of Malaria vectors. PLoS One. 2014;9(2):e89818.

33. Mease LE, Coldren RL, Musila LA, Prosser T, Ogolla F, Ofula VO, et al. Seroprevalence and distribution of arboviral infections among rural Kenyan adults: A cross-sectional study. Virol J. 2011;8(1):371.

34. Lutomiah J, Bast J, Clark J, Richardson J, Yalwala S, Oullo D, et al. Abundance, diversity, and distribution of mosquito vectors in selected ecological regions of Kenya: public health implications. J Vec Ecol. 2013;38(1):134-42.

35. Gubler DJ, Clark GG. Dengue/dengue hemorrhagic fever: the emergence of a global health problem. Emerg Infec Dis. 1995;1(2):55.

36. Edwards FW. Mosquitoes of the Ethiopian Region. III.-Culicine Adults and Pupae. London: Brit. Mus. (N. H.); 1941

37. Jupp PG. Mosquitoes of Southern Africa: Culicinae and Toxorhynchitinae. Hartebeespoort: Ekogilde Publishers; 1996

38. White GC, Bennetts RE. Analysis of frequency count data using the negative binomial distribution. Ecology. 1996;77:2549-57.

39. R Development Core Team: R: A language and environment for statistical computing. Vienna, Austria: R Foundation for Statistical Computing. 2010: ISBN 3-900051-900007-900050, URL http://www.R-project.org.

40. Dekker T, Takken W. Differential responses of mosquito sibling species Anopheles arabiensis and An. quadriannulatus to carbon dioxide, a man or a calf. Med Vet Entomol. 1998;12(2):136-40.

41. Vargo AM, Foster WA. Responsiveness of female Aedes aegypti (Diptera: Culicidae) to flower extracts. J Med Entomol. 1982;19(6):710-8.

42. Jepson PC, Healy TP. The location of floral nectar sources by mosquitoes: an advanced bioassay for volatile plant odours and initial studies with Aedes aegypti (L.) (Diptera: Culicidae). Bull Eentomol Res. 1988;78(4):641-50.

43. Kline D, Takken W, Wood J, Carlson D. Field studies on the potential of butanone, carbon dioxide, honey extract, l-octen-3-ol, L-lactic acid and phenols as attractants for mosquitoes*. Med Vet Entomol. 1990;4(4):383-91.

44. Blackwell A, Dyer C, WADHAMS L, MORDUE W. The role of 1-octen-3-ol as a host-odour attractant for the biting midge, Culicoides impunctatus Goetghebuer, and interactions of 1-octen-3-ol with a volatile pheromone produced by parous female midges. Physiol Entomol. 1996;21(1):15-9.

45. van der Goes van Naters W, Bootsma L, Den Otter C, Belemtougri R. Search for tsetse attractants: A structure-activity study on 1-octen-3-ol in Glossina fuscipes fuscipes (Diptera: Glossinidae). J Chem Ecol. 1996;22(2):343-55.

46. Harris AF, Nimmo D, McKemey AR, Kelly N, Scaife S, Donnelly CA, et al. Field performance of engineered male mosquitoes. Nature Biotechnol. 2011;29(11):1034-7.

47. Klun JA, Walter FS, Mustapha D. Stereochemical effects in an insect repellent. J Med Entomol. 2001;38(6):809-12.

48. Reisenman CE, Riffell JA, Bernays EA, Hildebrand JG. Antagonistic effects of floral scent in an insect-plant interaction. Proc Roy Soc Lond B: Biolog Sci. 2010;277(1692):2371-9. 